\title{
Psychmuse: A Macintosh system for psychomusicology research
}

\author{
MARILYN BOLTZ, MITESH KAPADIA, and RONALD JOYNER \\ Haverford College, Haverford, Pennsylvania
}

\begin{abstract}
A software system developed with HyperCard has been designed to support research relying on musical stimuli. The software accesses a set of digitized sounds in memory that consist of chromatic scale notes for the piano, harp, and guitar. Menu options allow experimenters to create monophonic melodies, to arrange melodies in a prescribed order, and to present them in a flexible format for a variety of psychological tasks. In addition to supporting experimental research projects, the software can also be used to demonstrate certain fundamental principles of auditory perception and cognitive psychology.
\end{abstract}

In recent years, the study of psychomusicology has become an increasingly popular area of research within cognitive psychology. In part, this stems from a quest to determine how musical relationships are represented in memory and subsequently used for both the production and perception of musical events (see Dowling \& Harwood, 1986; Handel, 1989; Sloboda, 1985, 1988, for excellent reviews). More generally, however, music is an example of an ecologically valid stimulus that characterizes the structural properties of many other naturalistic events. For example, the pattern of structural relations communicating different moods and emotions in music (Hevner, 1936; Levi, 1982; Rigg, 1964; Scherer \& Oshinsky, 1977) is strikingly similar to those within speech (Cosmides, 1983; Williams \& Stevens, 1979) and walking gaits (Montepare, Goldstein, \& Clausen, 1987; Sloman, Berridge, Homatidis, Hunter, \& Duck, 1982). Music also displays a hierarchical arrangement of nested structure (Deutsch \& Feroe, 1981; Jones \& Boltz, 1989; Lerdahl \& Jackendoff, 1983; Yeston, 1976) that generalizes to speech utterances and conversations (Grosjean, Grosjean, \& Lane, 1979; Jaffe \& Feldstein, 1970; Martin, 1972), locomotion patterns (Carlsoo, 1972; Pierson, 1976; Winter, 1983), narrative discourse (Mandler \& Johnson, 1977; Rumelhart, 1975; Thorndyke, 1977), and action schemes (Bower, Black, \& Turner, 1979; Newtson, 1973, 1976; Schank, 1982). Thus, given that music displays many structural regularities shared by other naturalistic events and is relatively easy to experimentally manipu-

\footnotetext{
This project was supported by Apple Computers through a grant awarded to the first author by the Consortium of Liberal Arts Colleges. The authors thank Eric Davies, Brian Knatz, Edmund Meyers, Jan Richard, Colin Rule, and Peter Tannenbaum for their assistance during various phases of this project. Requests for reprints should be addressed to Marilyn Boltz, Department of Psychology, Haverford College, Haverford, PA 19041 (E-mail address: M_BOLTZ@HVRFORD. BITNET or M_BOLTZ@ACC.HAVERFORD.EDU).
}

late, it is increasingly used to investigate higher order processes of selective attention, perceptual judgments, memory, and time-estimation activities.

As recently as 10 years ago, most psychologists were forced to rely on sine-wave approximations of music to achieve rigorous experimental control over various acoustical parameters. However, with the technological development of keyboards, synthesizers, and computerinterfaced MIDI systems, researchers are now able to simulate a wide range of high-fidelity instruments whose individual pitch, amplitude, and timing parameters can be precisely designated. Although this grants greater ecological validity to the auditory domain, software packages able to accommodate psychological research designs remain somewhat of a problem. Most commercial packages are designed for musical sequencing, editing recorded sounds, developing musical perception and production skills, or representing melodies by means of musical notation. In contrast, relatively few packages are available to generate musical events for presentation in a psychological experiment. One exception is a software system, termed MIDILAB, that was designed for an IBM computer (Todd, Boltz, \& Jones, 1989). When interfaced with a MIDI processing unit and synthesizer module, MIDILAB allows researchers to create and present musical stimuli for a variety of psychological tasks. It ensures precise control over all acoustical parameters and is able to collect data during on-line presentations for subsequent statistical analysis.

The system described here, Psychmuse, is modeled on MIDILAB but was developed for a Macintosh-based laboratory. Given the superior sound capabilities of the Mac, it requires no external peripheral devices to generate musical stimuli. The only necessary equipment is a Macintosh II or SE computer with a hard disk or a highdensity floppy drive and a minimum of $2.5 \mathrm{MB}$ of RAM. The following provides an overview of the experimental contexts that Psychmuse is designed to support. 


\section{Applications to Experimental Paradigms}

When conducting research in the area of psychomusicology, there are two fundamental requirements that any software package must be able to accommodate. The first is the ability to create a set of chromatic melodies for presentation in an experiment. Here, the experimenter must be able to specify the precise frequency, timing, and amplitude properties of each note, as well as the instrumental voice (e.g., piano, flute, guitar, etc.) of the melody itself. The second requirement is that once a set of melodies has been created for a given experiment, the experimenter must then be able to present these tunes, in a predetermined order, to subjects in the prescribed format of a particular task. Typically, melodies within a psychological experiment are presented over the course of several trials in which each trial consists of an initial warning tone (of a given frequency, duration, and amplitude) that is then followed by the presentation of either one, two, or three melodies. During a fixed response period that immediately follows, subjects are then required to perform some sort of task before the warning tone recurs to signal the onset of the next trial. The kinds of tasks that subjects might perform during this response period may include any one of the following:

Melody recall. A major issue within psychomusicology concerns what types of structural characteristics make some tunes easier to learn and remember than others. Thus, the experimenter may covary the pitch and temporal arrangement of a set of tunes and, on a given trial, require subjects to reproduce a melody they have just heard through musical notation (Boltz, 1991a; Boltz \& Jones, 1986; Deutsch, 1980).

Perceptual judgment. Another area of research has assessed listeners' reactions to melodies on a variety of perceptual dimensions. These may include ratings for the degree of phrase or musical completion (Boltz, 1989a, 1989b; Cuddy \& Badertscher, 1987; Krumhansl, 1979; Palmer \& Krumhansl, 1987a, 1987b), experienced tension (Povel, 1985), tonality and harmonic consonance (Butler \& Brown, 1984), or perceived affect (Levi, 1982; Scherer \& Oshinsky, 1977).

Time estimation. Several recent studies have relied on musical events to investigate time-estimation activities (e.g., Boltz, 1989c, 1991b; Jones \& Boltz, 1989; Kowal, 1981). A major thrust of this research concerns the "filled interval effect," wherein two equivalent intervals of time are not always judged to be the same duration. Thus, by asking subjects to compare the relative duration of paired melodies, effects due to characteristics of natural event structure can be examined.

Melody recognition. Comparative judgment tasks have also been used to study the immediate memory of musical events and how certain structural relationships seem to make melodies perceptually similar to one another. The strategy is to present a pair of melodies and ask subjects to indicate whether they are the "same" or "different," as well as a confidence-level judgment (e.g., Bharucha
\& Pryor, 1986; Dowling, 1978; Kidd, Boltz, \& Jones, 1984; Monahan \& Carterette, 1985). An alternative format involves a two-alternative forced-choice task in which listeners must decide which of two comparison melodies best match a preceding standard melody (e.g., Boltz, Marshburn, Jones, \& Johnson, 1985; Cuddy \& Cohen, 1976; Cuddy, Cohen, \& Miller, 1979).

In sum, a software package implementing these various tasks must ensure the occurrence of a precisely timed sequence of events within a set of experimental trials. Psychmuse does this and offers a user-friendly environment in which to quickly construct and execute a given psychological experiment.

\section{Program Description}

Psychmuse was developed ${ }^{1}$ with the use of HyperCard 1.5, a high-level programming environment for the Macintosh. HyperCard was chosen over more conventional languages such as $\mathrm{C}$ or Pascal because of its userfriendliness and ease of customization. There are, however, some limitations of HyperCard that are particularly relevant for the programming of auditory sounds. One concerns the resolution of timed events. In contrast to other programming languages, HyperCard relies on a "tick" as its smallest unit of time. Since a tick is equal to $1 / 60$ of a second, the timing resolution of all durational values is therefore $16-17 \mathrm{msec}$. A second limitation involves the amplitude, or loudness, level of sounds that are generated from a HyperCard program. This parameter can only be accessed through the Macintosh's control panel. Thus, for a particular set of experimental trials, Psychmuse will not allow its users to specify different amplitude levels for different melodies, or different notes within a melody. Although Psychmuse will ensure that amplitude remains constant within an experiment, the overall amplitude level can only be specified within the control panel or, alternatively, on an external amplifier that might be interfaced with the computer.

The sounds that Psychmuse accesses are digitized samples of chromatic scale notes from three different instruments: piano, harp, and guitar. Each note has been individually recorded to avoid the distorting effects of "rate scaling," the increase or decrease of a sample's frequency by compressing or extending its playback. Notes from the piano and guitar span five octaves, from $C$ of the second (C2) to $\mathrm{C}$ of the seventh octave (C7), whereas the harp spans four octaves, from $\mathrm{C} 3$ to $\mathrm{C} 7$.

An Ensoniq EPS keyboard sampler provided the source of the digitized samples. The EPS digitizes sound at a rate of $44.6 \mathrm{kHz}$ with a 16-bit resolution and thereby produces a quality of sound equal to that of a compact-disc recording. Ensoniq engineers recorded the instruments in studios and furnished the samples as part of the EPS sound library. The EPS samples of the three instruments used here were recorded onto a Macintosh II via the Farallon MacRecorder, a sound digitizer that operates at a rate of $22 \mathrm{kHz}$ with an 8-bit resolution but, nonetheless, is able 
to capture LP sound quality. These digitized samples were then saved as an SND resource, the Macintosh unit of sound storage.

Two Macintosh computers were used in the recording process. One was interfaced with the EPS sampler whose output fed into the MacRecorder connected to a serial port of the second computer. Since it was important to obtain uniform dynamics in the production of all notes, the software package Performer (published by Mark of the Unicorn) was used to "play" the EPS. With the use of Professional Composer, a notation software package also by Mark of the Unicorn, each 12-note octave was represented by a series of whole notes separated by whole rests. Performer then executed this sequence at a metronome marking of $60 \mathrm{bpm}$ or an on-time of $4 \mathrm{sec} /$ note. This duration was chosen to provide experimenters with a wide range of note durations and thereby enhance the flexibility of the program.

One advantage of using the Performer software package to record digitized sounds is that the perceived amplitude of notes across octaves can be equated. This is achieved by specifying a uniform velocity (i.e., force with which a given note is played) for all notes in the digitization process. Although amplitude or apparent loudness level will show some variations across instruments ${ }^{2}$ because of the inherent timbre, all notes within a given instrument will display a uniform amplitude.

Because of memory constraints, Psychmuse in its packaged form only contains the piano samples in memory. However, the harp and guitar samples can easily be added with the program ResEdit. Each of these two instruments requires 1.0-1.5 MB of memory in addition to the 2.5 MB needed to run the basic program. The sounds that a user intends to access for a given experiment must all be preloaded into memory-otherwise, disk access time will be too slow and the overall timing resolution of experimental events will markedly decrease. Finally, if a user wishes to increase the program's repertoire of sounds, additional octaves or other instruments can be digitized by using the procedure outlined above.

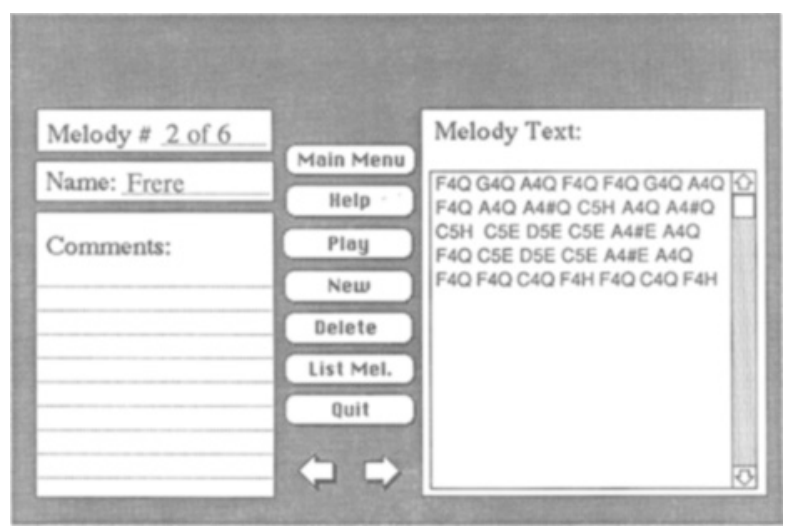

Figure 1. Phase 1: Creating a series of melodies.

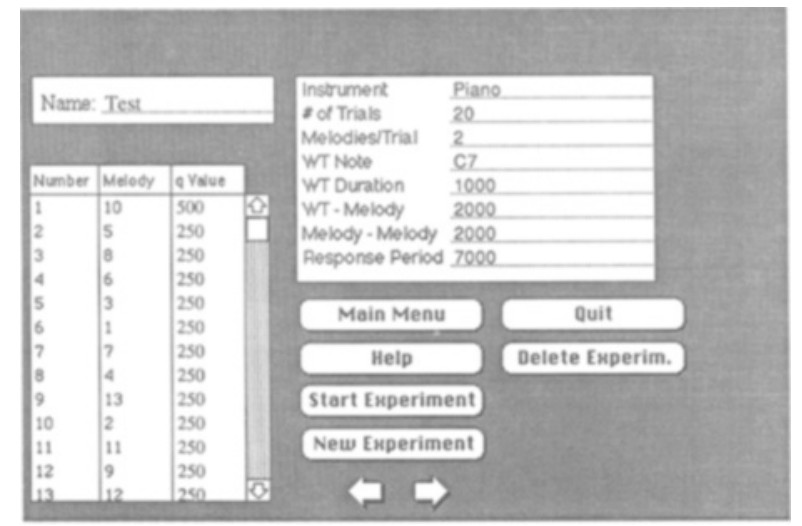

Figure 2. Phase 2: Experimental Setup.

The main menu of Psychmuse depicts the two phases required to set up an experiment. The first involves "creating a set of melodies" as experimental stimuli. Within this card, shown in Figure 1, the user creates a new melody by simply clicking on the "New" button and providing a name for the tune in the box to the left. The sequence of notes, along with their respective durational values, is then entered under the "Melody Text" window. ${ }^{3}$ To illustrate, Figure 1 depicts the arrangement of notes comprising "Frère Jacques." 4 Notice that each successive note, separated by a blank space, can contain up to five values. The first refers to a given diatonic note (i.e., CDEFGAB), the second to the desired octave of the note (i.e., 2nd, 3rd, 4th, 5th, or 6th), and the third to a sharp ( $:$, if one exists. The final two values refer to the note's duration, $\mathrm{Q}=$ quarter note $(d), \mathrm{E}=$ eighth note $(\delta), H=$ half note $(d)$, and $W=$ whole note $(0)$. A period following any of these codes ensures dotted durational values. Rests can also be specified by the symbol $\mathrm{Rx}$, in which $\mathrm{x}$ equals the millisecond time duration of the desired silence period. After the sequence of notes has been entered, the melody is automatically saved and stored within a common tune file that can later be viewed with the "List Mel." button. At this stage, the user also has the option of hearing a melody by clicking on the "Play" button. Finally, the sequence of notes for a given melody within the common tune file can be displayed by clicking on the arrow buttons so that, if the user wishes, old notes can be modified and new ones added.

Once a set of melodies has been created for a given experiment, the user returns to the main menu and selects the "Experimental Setup" option. The card that is then displayed is shown in Figure 2. Here, the user first provides a name for the experiment and then types in a series of numbers specifying which melodies will occur on a given trial, as well as the overall order in which all melodies will be presented. For example, if one is conducting an experiment consisting of 20 trials in which each trial presents 2 melodies, one would type in a sequence of 40 numbers that each reflect a particular melody from the com- 
mon tune file (e.g., the sequence of $10,5,8,6 \ldots$ indicates that the 10th melody from the tune file will be played followed by the 5 th tune, the 8 th tune, and so on). The millisecond value for a quarter note is also indicated in this window and, as seen in Figure 2, can be modified for each individual melody. The value specified here is also used by the program to automatically determine the durations of eighth, half, and whole notes. For example, if a quarter note is set to a value of $500 \mathrm{msec}$, then an eighth note will automatically be defined as $250 \mathrm{msec}$, a dotted eighth note as $375 \mathrm{msec}$, a half note as $1,000 \mathrm{msec}$, and so on. In its current version, Psychmuse has been programmed to rely on ratio time relations across notes within a given melody; therefore, other kinds of timing relationships are not available.

The final phase of experimental setup consists of specifying the overall format of melody presentation and the sequence of events for a given trial. These specifications include:

1. The particular instrument in which all tunes are played (i.e., piano, harp, or guitar).

2. The number of total trials within the experiments (e.g., 20 but no limit).

3. The number of melodies presented within a given trial (i.e., 1, 2, or 3).

4. The diatonic pitch value of the warning tone (e.g., C7).

5. The duration of the warning tone (in milliseconds).

6 . The time (in milliseconds) between the warning tone and the first melody of a trial.

7. The time (in milliseconds) between melodies of a trial.

8. The durational length (in milliseconds) of the response period.

These specifications are automatically saved in memory, and a user can retrieve previous experimental setups by using the arrow keys. By clicking on the "Start Experiment" button, the sequence of trials will be played for immediate presentation or, alternatively, for recording onto cassette tapes for later presentation. Since the Macintosh speaker is monophonic and of limited quality, a user may want to output sound through a stereo jack and into an amplifier and a set of speakers. This not only will improve the quality of sound but also will enable one to make adjustments with respect to the psychoacoustics of a given room. Psychmuse is currently unable to collect data from the keyboard console, but subjects' written responses can be indicated on provided forms that are appropriate to a given task.

The system is user-friendly, since no manual is required for its operation. Little prior computer knowledge or sophistication is needed to run the program. The various menu prompts are all self-explanatory and help options are available throughout each phase.

In sum, Psychmuse provides an efficient and inexpensive tool with which to conduct psychomusicology re- search. Its primary drawbacks concern the resolution of timed events and its inability to manipulate amplitude within a given experiment. These two problems, however, can be overcome with a MIDI-interfaced system that relies on a keyboard and/or synthesizer for sound production. For example, the MIDILAB system designed for the IBM computer (Todd, Boltz, \& Jones, 1989) not only ensures a 2-msec timing resolution for all events but also offers precise control over amplitude variations, a wider selection of instruments, the flexibility of creating chords and simultaneous melodic lines, and the ability to collect and analyze data from various response systems. Given that sound is generated from external peripheral devices, the amount of computer memory that remains available to a user is also significantly increased. Psychmuse has sacrificed these capabilities in the interest of cost. MIDI sound equipment can be relatively expensive and can easily exceed the budget for an undergraduate research facility. Thus, although Psychmuse is much less sophisticated than the IBM MIDILAB system and is unable to support a MIDI-interface system, its reliance on digitized sounds eliminates the need for any additional equipment support.

Psychmuse offers a number of applications within both laboratory and classroom settings. It is not only designed to support faculty research but also can be of help in student projects that are often required in many experimental methods and cognitive psychology courses. In fact, when this system is used in conjunction with MacLaboratory (Chute, 1986), MacLab (Costin, 1988) and other similar packages (e.g., Anderson \& Lane, 1987; Bharucha, Meike, \& Baird, 1987; Jensen, 1987), a wide variety of experiments can be conducted with auditory, verbal, or visual stimuli. Similarly, Psychmuse provides a classroom teaching aid in which certain principles of auditory perception and cognitive psychology can be readily demonstrated. For example, by interleaving melodies from different octaves, effects caused by auditory streaming (Bregman, 1978a, 1978b, 1978c) and figure-ground relations (Dowling, 1973) can be observed and further explored. Other phenomena of interest may include auditory illusions (Deutsch, 1975); the filled-interval effect (Boltz, 1989c, 1991b; Jones \& Boltz, 1989); or rhythmic organization (Fraisse, 1956, 1974, 1978, 1982; Handel, 1973, 1974, 1984; Povel, 1981, 1984; Povel \& Essens, 1985).

Finally, a more versatile version of Psychmuse is being developed that allows one to specify the trial-sequencing format for various kinds of auditory sounds. By using the MacRecorder or some other digitization system (see Gibson, 1987, for a review), stimuli in the form of human voices, bird songs, speech, recorded symphonies, or miscellaneous sound effects can all be inputted to the Macintosh and stored in memory. ${ }^{5}$ These sounds can then be arranged in a predetermined order and presented according to the options shown in Figure 2. Thus, this more flexible version of the program will allow one to conduct research with a greater range of auditory stimuli. 


\section{Software Availability}

Psychmuse is public domain software; readers interested in receiving a copy should provide the first author with three double-sided, double-density 3.5" disks and $\$ 5.00$ to cover postage and handling costs.

\section{REFERENCES}

Anderson, L. A. \& LANE, D. M. (1987). Demonstration experiments in perception and cognitive psychology for the Macintosh computer. Behavior Research Methods, Instruments, \& Compusers, 19, 249-251.

Bharucha, J. J., Meike, B. B Baird, J. C. (1987). The Macintosh as a user-friendly laboratory for perception and cognition. Behavior Research Methods, Instruments, \& Computers, 19, 131-134.

Bharucha, J. J., \& Pryor, J. H. (1986). Disrupting the isochrony underlying rhythm: An asymmetry in discrimination. Perception \& Psychophysics, 40, 137-141.

BolTz, M. (1989a). Perceiving the end: Effects of tonal relationships on melodic completion. Joumal of Experimental Psychology: Human Perception \& Performance, 15, 749-761.

BoLTz, M. (1989b). Rhythm and "good endings" : Effects of temporal structure on tonality judgments. Perception \& Psychophysics, 46, 9-17.

BoLTZ, M. (1989c). Time judgments of musical endings: Effects of expectancies on the "filled interval effect." Perception \& Psychophysics, 46, 409-418

BoLtz, M. (1991a). Some structural determinants of melody recall. Memory \& Cognition, 19, 239-251.

Boltz, M. (199lb). Time estimation and attentional perspective. Perception \& Psychophysics, 49, 422-433.

Boltz, M., Jones, M. (1986). Does rule recursion make melodies easier to reproduce? If not, what does? Cognitive Psychology, 18, 389-431.

Boltz, M., Marshburn, E., Jones, M. R., Johnson, W. W. (1985). Serial-pattern structure and temporal-order recognition. Perception \& Psychophysics, 37, 209-217.

Bower, G., Black, J., TuRner, T. (1979). Scripts in memory for text. Cognitive Psychology, 11, 177-220.

Bregman, A. S. (1978a). Auditory streaming: Competition among alternative organizations. Perception \& Psychophysics, 23, 391-398.

Bregman, A. (1978b). Auditory streaming is cumulative. Journal of Experimental Psychology: Human Perception \& Performance, 4, 380-387.

Bregman, A. (1978c). The formation of auditory streams. In J. Requin (Ed.), Atention and pefformance VII (pp. 63-75). Hillsdale, NJ: Erlbaum.

Butler, D., Brown, H. (1984). Tonal structure versus function: Studies of the recognition of harmonic motion. Music Perception, 2, 6-24.

Carlsoo, S. (1972). How man moves (W. P. Michael, Trans.). New York: Distributed by Cran, Russak, \& Co.

Chute, D. L. (1986). MacLaboratory for psychology: General experimental psychology with Apple's Macintosh. Behavior Research Methads, Instruments, \& Computers, 18, 205-209.

Cosmides, L. (1983). Invariances in the acoustic expression of emotion during speech. Joumal of Experimental Psychology: Human Perception \& Performance, 9, 864-881.

Costin, D. (1988). MacLab: A Macintosh system for psychology labs. Behavior Research Methods, Instruments, \& Computers, 20, 197-200.

CudDY, L., L., BADERTSCHER, B. (1987). Recovery of the tonal hierarchy: Some comparisons across age and levels of musical experience. Perception \& Psychophysics, 41, 609-620.

CUdDY, L., \& COHEN, A. (1976). Recognition of transposed melodic sequences. Quarterly Joumal of Experimental Psychology, 28, 255-270.

Cuddy, L., Cohen, A., \& Miller, J. (1979). Melody recognition: The experimental application of musical rules. Canadian Joumal of Psychology, 33, 148-157.

Deutsch, D. (1975). Musical illusions. Scientific American, 233, 92-104.
DeutsCH, D. (1980). The processing of structured and unstructured tonal sequences. Perception \& Psychophysics, 28, $381-389$.

DEUTSCH. D., FEROE, J. (1981). The internal representation of pitch sequences in tonal music. Psychological Review, 85, 503-522.

Dowling, J. (1973). The perception of interleaved melodies. Cognitive Psychology. 5, 322-337.

Dow LiNG, J. (1978). Scale and contour: Two components of a theory of memory for melodies. Psychological Review, 85, 341-354.

Dowling, J., Harwood, D. (1986). Music cognition. New York: Academic Press.

Fraisse, P. (1956). Les structures rythmiques. Louvain, Belgium: Publication Universitaires de Louvain.

Fraisse, P. (1974). Psychologie du rythme. Paris: Presses Universitaires de France.

Fraisse, P. (1978). Time and rhythm perception. In E. C. Carterette \& M. P. Friedman (Eds.), Handbook of perception, Vol. 8: Perceptual coding. New York: Academic Press.

Fraisse, P. (1982). Rhythm and tempo. In D. Deutsch (Ed.), The psychology of music (pp. 149-180). New York: Academic Press.

GıBson, J. M. (1987). Using digitized auditory stimuli on the Macintosh computer. Behavior Research. Methods, Instruments. \& Computers, 19, 257-259.

Grosjean, F., Grosjean, L., Lane, H. (1979). The patterns of silence: Performance structures in sentence production. Cognitive Psychology, 11, 58-81.

HANDEL, S. (1973). Temporal segmentation of repeating auditory patterns. Joumal of Experimental Psychology, 101, 46-54.

HANDEl, S. (1974). Perceiving melodic and thythmic auditory patterns. Joumal of Experimental Psychology, 103, 922-933.

Handel, S. (1984). Using polyrhythms to study rhythm. Music Perception, 1, 465-484.

HANDEL, S. (1989). Listening: An introduction to the perception of auditory events. Cambridge, MA: MIT Press.

HEVNER, K. (1936). Experimental studies of the elements of expression in music. American Joumal of Psychology, 48, 246-268.

JAFFE, J., \& FeLDSTEIN, S. (1970). Rhythms of dialogue. New York: Academic Press.

JENSEN, D. G. (1987). Facial perception studies using the Macintosh. Behavior Research Methods, Instruments, \& Computers, 19, 252-256.

JONES, M., BoltZ, M. (1989). Dynamic attending and responses to time. Psychological Review, 96, 459-491.

KidD, G., Boltz, M., Jones, M. (1984). Some effects of thythmic context on melody recognition. American Joumal of Psychology, 97. 153-173.

KowAL, K. (1981). Growth of apparent duration: Effect of melodic and non-melodic tonal variation. Perceptual \& Motor Skills, 52, 803-817.

KRUmhansL, C. (1979). The psychological representation of musical pitch in a tonal context. Cognitive Psychology, 11, 346-374.

LERDAHL, F., \& JACKENDOFF, R. (1983). A generative theory of tonal music. Cambridge, MA: MIT Press.

LEVI, D. (1982). The structural determinants of melodic expressive properties. Journal of Phenomenological Psychology, 13, $19-40$.

MANDLER, J., JohNSON, N. (1977). Remembrance of things parsed: Story structure and recall. Cognitive Psychology, 9, 111-151.

MARTIN, J. (1972). Rhythmic (hierarchical) versus serial structure in speech and other behavior. Psychological Review, 79, 487-509.

Monahan, C., Carterette, E. (1985). Pitch and duration as determinants of musical space. Music Perception, 3, 1-32.

Montepare, J., Goldstein, S., Clausen, A. (1987). The identification of emotions from gait information. Joumal of Nonverbal Behavior, 11, 33-42.

Newtson, D. (1973). Attribution and the unit of perception of ongoing behavior. Joumal of Personality \& Social Psychology, 28, 28-38.

NewTson, D. (1976). Foundations of attribution: The unit of perception of ongoing behavior. In J. Harvey, W. Ickes, \& R. Kidd (Eds.), New directions in attribution research (pp. 223-247). Hillsdale, NJ: Erlbaum.

Palmer, C., \& KrumhanSL, C. (1987a). Independent temporal and pitch structures in determination of musical phrase. Joumal of Experimental Psychology: Human Perception \& Performance, 13, 116-126. 
Palmer, C., \& Krumhansl, C. L. (1987b). Pitch and temporal contributions to musical phrase perception: Effects of harmony, performance timing, and familiarity. Perception \& Psychophysics, 41, 505-518.

Pierson, K. (1976). Control of walking. Scientific American, 235, 72-86.

Povel, D. (1981). Internal representations of simple temporal patterns. Journal of Experimental Psychology: Human Perception \& Performance, 7, 3-18.

Povel, D. (1984). A theoretical framework for rhythm perception. Psychological Research, 45, 315-337.

Povel, D. (1985). Time, rhythms, and tensions: In search of the determinants of rhythmicity. In J. Michon \& J. Jackson (Eds.), Time, mind, and behavior (pp. 215-225). New York: Springer-Verlag.

Povel, D., Essens, P. (1985). Perception of temporal patterns. Music Perception, 2, $411-440$.

RigG, M. (1964). The mood effects of music: A comparison of data from four investigators. Journal of Psychology, 58, 427-438.

RUMElHART, D. (1975). Notes on a schema for stories. In D. Bobrow \& A. Collins (Eds.), Representation and understanding: Studies in cognitive science (pp. 265-303). New York: Academic Press.

Schank, R. (1982). Dynamic memory. New York: Cambridge University Press.

SCHERER, K., OshINsKy, I. (1977). Cue utilization in emotion attribution from auditory stimuli. Motivation \& Emotion, 1, 331-346.

SLOBODA, J. (1985). The musical mind: The cognitive psychology of music. New York: Oxford University Press.

SLOBODA, J. (1988). Generative processes in music: The psychology of performance, improvisation, and composition. Oxford, U.K.: Clarendon Press.

Sloman, L., Berridge, M., Homatidis, S., Hunter, D., \& Duck, T. (1982). Gait patterns of depressed patients and normal subjects. American Journal of Psychiatry, 139, 94-97.

ThORNDYKE, P. (1977). Cognitive structures in comprehension and memory of narrative discourse. Cognitive Psychology, 9, 77-110.

ToDD, R., Boltz, M., a JoNEs, M. (1989). The MIDILAB auditory research system. Psychomusicology, 8, 83-96.

Williams, C., \& STevens, K. (1979). Emotions and speech: Some acoustical correlates. In S. Weitz (Ed.), Nonverbal communication (pp. 233-248). New York: Oxford University Press.

WINTER, D. (1983). Biomechanical motor patterns in normal walking. Journal of Motor Balance, 15, 302-330.

YESTON, M. (1976). The stratification of musical rhythm. New Haven: Yale University Press.

\section{NOTES}

1. Psychmuse was designed by the first and third authors and programmed by the second. The third author was also responsible for sound digitization.

2. Although the velocity of notes was held constant during the digitizing process, users should note that different instruments display different profiles of attack and decay times. In general, notes from a harp and guitar decay more quickly than those from a piano. This factor becomes relevant when one considers that all digitized sounds in the present system were inputted with a 4-sec tonal duration. Thus, if one is primarily relying on short durations for a given melody (e.g., $d=200 \mathrm{msec}$ ), notes from the piano will sound rather "abrupt" and "staccato" because a note's duration has not yet reached its point of decay. On the other hand, the piano is an ideal instrument to use when tonal durations are relatively longer. Conversely, the harp and guitar will sound more natural at relatively short durations (because of the quick decay) but are less ideal for relatively longer durations.

3. In its current form, this software is only capable of presenting monophonic melodies. It is unable to generate chords or simultaneous treble/bass melodic lines.

4. Adapted from The International Library of Music: Invitation to the Piano (p. 27) by A. Broido \& F. Greissle of The University Society, 1964, New York: The University Society, Inc.

5. The primary drawback of sound digitalization is the large amount of memory required to store such stimuli. To some extent, however, this problem can be circumvented through file-compression techniques.

(Manuscript received December 31, 1990; revision accepted for publication March 25, 1991.) 